\title{
Ets-related protein PU.1 regulates expression of the immunoglobulin J- chain gene through a novel Ets-binding element
}

\author{
Myung K. Shin and Marian Elliott Koshland \\ Immunology Division, Department of Molecular and Cell Biology, University of California, Berkeley, California 94720 USA
}

\begin{abstract}
In a primary immune response, a signal from interleukin-2 (IL-2) activates transcription of the gene encoding the pentamer IgM joining component, the J chain. Recently, a bifunctional control element $(\mathrm{JB})$ in the J-chain promoter has been identified. This finding was pursued in the present study by purifying and characterizing the nuclear protein (NF-JB) that mediates the positive regulatory activity of the JB element. The analyses revealed that NF-JB is identical to the Ets-related B-cell- and macrophage-specific transcriptional factor, PU.1, despite the fact that the JB site lacks the GGA core reported to be essential for binding by members of the Ets oncoprotein family. The two factors were found to be indistinguishable with respect to their DNA-binding characteristics, size, and peptide structure. Moreover, in transient transfection assays, PU.1 alone activated reporter constructs containing the JB cis-element, and the activation was shown to be dependent on a glutamine-rich sequence in the amino-terminal portion of PU.1. Finally, a dominant negative mutant of PU.1 was capable of suppressing the transcriptional activity of a $1.2-\mathrm{kb}$ J-chain promoter sequence. These results establish an important role for PU.1 in the regulation of immunoglobulin J-chain gene expression and provide new insights into the function(s) of the Ets transcription factors in lymphoid cells.
\end{abstract}

[Key Words: Ets; PU.1; immunoglobulin J-chain gene; interleukin-2; transcription]

Received July 12, 1993; revised version accepted August 9, 1993.

In a primary immune response, $\mathrm{B}$ cells are triggered by antigen recognition and $\mathrm{T}$-cell-derived lymphokines to differentiate into pentamer IgM-secreting cells. One of the critical events in the differentiative process is the synthesis of the J-chain protein required for the assembly and secretion of pentamer IgM antibody (for review, see Koshland 1985). Studies of both normal B cells and model B-cell lines have shown that J-chain synthesis is tightly regulated at the transcriptional level. The gene is transcribed only in antigen-activated B cells and only in response to signals delivered by either of two T-cell lymphokines, interleukin-2 (IL-2) or interleukin 5 (IL-5) (Nakanishi et al. 1984; Blackman et al. 1986; Matsui et al. 1989). Correlating with the IL-2/IL-5-induced J-chain gene transcription is the development of a nuclease hypersensitive site that spans bp -170 to +88 relative to the transcription start site (Minie and Koshland 1986).

Sequence analysis of the hypersensitive site of the J-chain promoter did not reveal any functional binding sites for known ubiquitous or lymphoid-specific transcription regulators (Mitchell and Tjian 1989; Staudt and Lenardo 1991). However, deletion and mutational analyses defined a major control region located in the middle of the hypersensitive site $(-75$ to -45$)$ that encodes two adjacent control elements. One, the cis-element termed
JB, contains overlapping positive and negative regulatory motifs and acts as a repressor in J-chain-silent B cells and as an activator in J-chain-expressing cells (Lansford et al. 1992 ).

Studies of the JB element have identified a nuclear factor, NF-JB, that mediates its positive regulatory activity. The NF-JB protein recognizes a 9-bp purine-rich sequence located at -56 to -48 in the J-chain promoter. Single- or double-base changes that abrogate NF-JB binding were found to nullify the stimulatory activity of the IB element in a heterologous promoter assay. More strikingly, mutations of the NF-JB recognition site in the context of $1.2 \mathrm{~kb}$ of J-chain promoter resulted in an 8 - to 12 -fold reduction in the promoter activity (Lansford et al. 1992|. These observations suggested that NF-JB plays a critical role in tissue- and developmental-specific regulation of the J-chain gene.

In the studies reported here, we purified NF-JB and found it to be identical to PU.1, an Ets-related nuclear protein that is expressed specifically in B cells and macrophages (Klemsz et al. 1990). Members of the Ets family share a DNA-binding motif of $\sim 85$ amino acids that recognizes a purine-rich sequence with the core motif 5 'GGAA/T-3' (Karim et al. 1990; Macleod et al. 1992; Nye et al. 1992). PU.1 is one of several Ets proteins that has 
been directly demonstrated to function as a transcriptional activator; others include Ets-1, Ets-2, SAP-1, and PEA 3 (Bosselut et al. 1990; Klemsz et al. 1990; Wasylyk et al. 1990; Dalton and Treisman 1992; Xin et al. 1992). PU. 1 is also one of several Ets proteins that functions as an oncogene, inducing erythrolcukemia in mice (Moreau-Gachelin et al. 1988; Goebl 1990). Like other Ets proteins, however, very little is known about the ccllular genes that are regulated by PU.1. Recently, evidence was obtained that PU.1 contributes to immunoglobulin $\mathrm{k} 3$ ' enhancer function by interacting with an adjacently bound factor (Pongubala et al. 1992,1993).

In this report we demonstrate by in vivo cotransfection assays that PU. 1 regulates the expression of another immunologically significant gene, the J chain. We present evidence that the regulation is mediated through (1) a novel ets-binding site (Karim et al. 1990; Macleod et al. 1992; Nyc et al. 1992) and (2) a 30-amino acid activating sequence rich in glutamine. Furthermore, we show that, unlike the immunoglobulin $\kappa 3^{\prime}$ enhancer system, activation of J-chain gene transcription by PU.1 does not require protein-protein interaction with an adjacently bound nuclear factor.

\section{Results}

\section{Purification of NF-IB}

The J-chain transcription factor NF-JB was purified to apparent homogeneity by standard chromatographic procedures (Fig. 1). The first step, fractionation of lymphoma nuclear extracts on a cationic exchange resin, provided a 50- to 100 -fold enrichment. NF-JB was then isolated from these fractions by DNA affinity chromatography (Kadonaga and Tjian 1986). After three successive passages through resin conjugated with a JB sitespecific oligonucleotide, only a single protein species with an estimated molecular mass of $40-42 \mathrm{kD}$ was detectable by SDS-PAGE (Fig. 1).

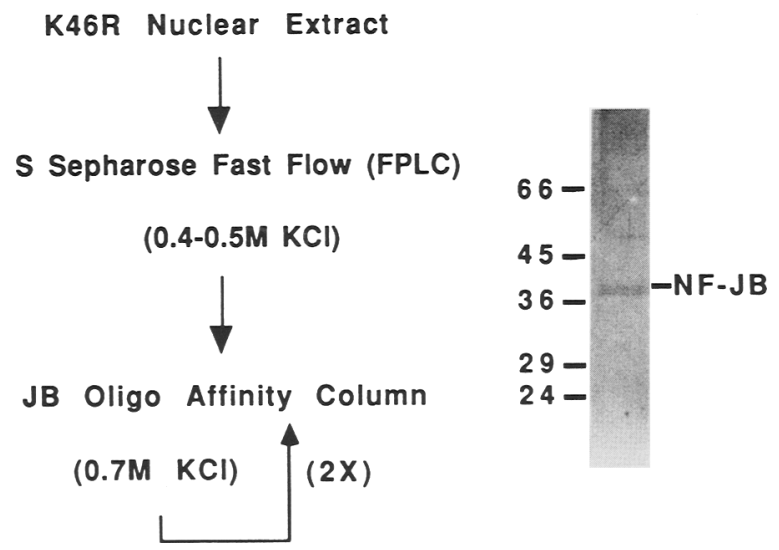

Figure 1. Purification of NF-JB protein. Scheme used for the purification of NF-JB from nuclear extracts of the mature B cell line K46R. (right) A silver-stained SDS gel of the purified fraction. The relative positions of molecular mass standards are indicated.

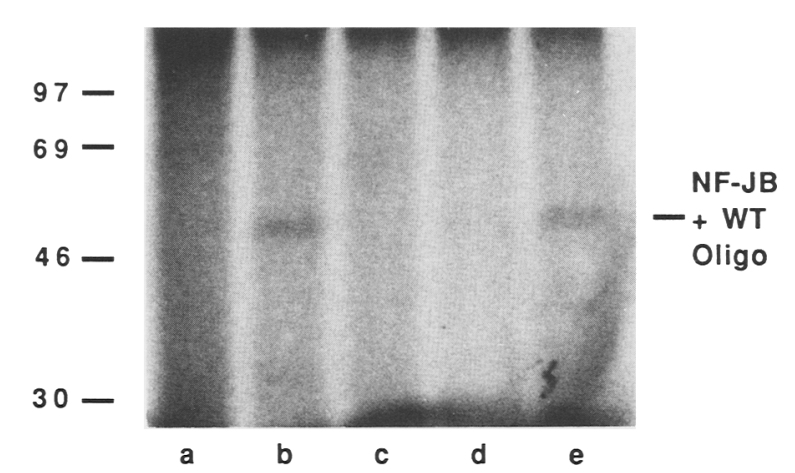

Figure 2. Binding specificity of purified NF-JB. UV cross-linking of the JB oligonucleotide without NF-JB (lane $a$ ), with NF-JB (lane $b$ ), with NF-JB but without UV treatment (lane $c$ ), with NF-JB in the presence of excess unlabeled JB oligonucleotide (lane $d$ ), and with NF-JB in the presence of excess unlabeled mutant JB oligonucleotide (lane e).

The binding specificity of the DNA-affinity purified material was ascertained by UV cross-linking /Chodosh 1991). The protein was incubated with radiolabeled BrdU-substituted JB oligonucleotide, the mixture was exposed to UV light, and the products of the reaction were analyzed by SDS-PAGE. The analyses revealed a single cross-linked complex (Fig. 2, lane b) that corresponded in size $(50 \mathrm{kD})$ with that expected by the linkage of NF-JB $(40-42 \mathrm{kD})$ to a denatured 28 -bp target sequence. The $50-\mathrm{kD}$ complex was not detected in the absence of the NF-JB protein or in the absence of a UV treatment (Fig. 2, lanes a,c). Moreover, the complex was shown by competition to represent a specific proteinDNA interaction; formation of the cross-linked product was prevented by the addition of excess unlabeled JB oligonucleotide but not by the addition of excess mutant JB oligonucleotide (Fig. 2, lanes d, el.

The binding specificity of the purified NF-IB was further defined by methylation interference footprinting using as probe a 75-bp J-chain promoter fragment that spanned the JB-binding site. As shown in Figure 3A, the $\mathrm{JB}$ protein bound a 9 -bp region on the coding strand that included two guanosines at positions -50 and -53 and the adenosines located between positions -47 and -57 . No interference with piperidine cleavage was detected on the noncoding strand (data not shown). The methylation pattern obtained with the DNA-affinity-purified NF-JB was identical to the footprint generated with B-lymphoma and myeloma crude nuclear extracts (Lansford et al. 1992).

\section{Identification of NF-JB as the ets-related oncoprotein PU.1}

A search of previously identified DNA-binding sites revealed a strong homology between the purine-rich sequence recognized by NF-JB and that recognized by a B-cell- and macrophage-specific transcription factor, PU.1 (Klemsz et al. 1990). Although the NF-JB site lacks the invariant GGA core \{Fig. 3B\}, which has been shown 
A

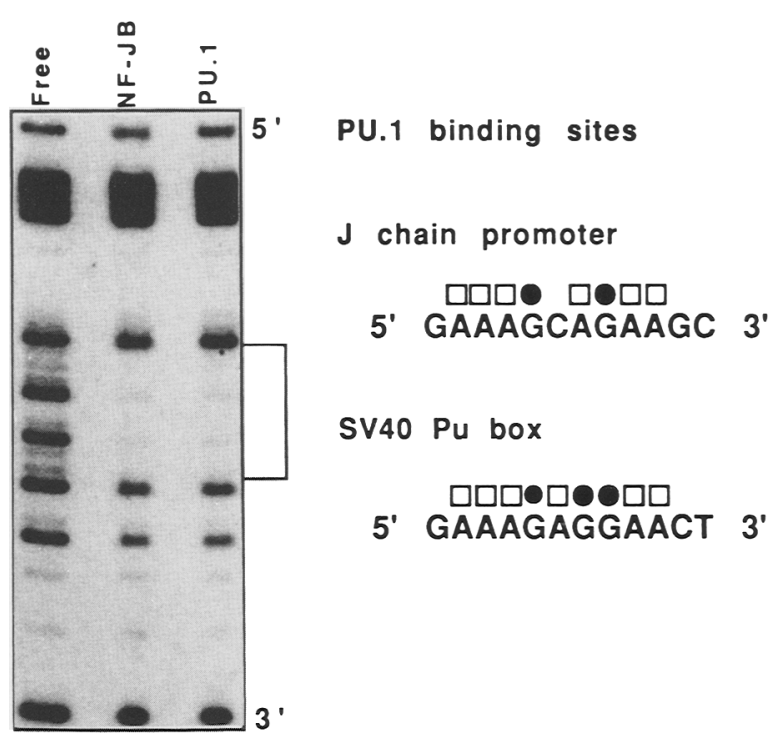

Figure 3. Dimethylsulfate (DMS) interference analyses with purified NF-JB and PU.1. $(A \mid$ Methylation interference patterns observed on the coding strand of the J-chain promoter probe, a 75-bp Pstl-HaeIII fragment spanning bp -83 to -8 . The area footprinted by both proteins is bracketed. $(B)$ Comparison of the DMS interference patterns on the J-chain promoter element, JB, and the SV40 Pu box. ( and $\square$ ) Contact guanosines and adenosines, respectively. The SV40 Pu box data was adapted from Pettersson and Schaffner (1987).

by site-specific mutation to be essential for binding by the Ets domain proteins (Karim et al. 1990; Nye et al. 1992; Wang et al.1992), detailed comparisons of the properties of NF-JB and PU.1 showed that the two factors were identical. First, in vitro-synthesized PU.1, like NF$\mathrm{JB}$, was found to migrate as a $40-$ to $42-\mathrm{kD}$ protein on SDS-PAGE (data not shown). The discrepancy between its predicted molecular size of 28-29 kD (Klemsz et al. 1990 ) and the experimentally determined value may have been the consequence of a high proline content $(7 \%)$. Second, the binding specificities of the two factors were found to be indistinguishable by several criteria. Gel mobility shift assays showed that in vitro-synthesized PU.1 bound strongly to the JB oligonucleotide and the resulting complex had the same mobility on polyacrylamide gel as the complex formed with DNA-affinity-purified NF-JB (Fig. 4, lanes 2,4). Moreover, when rabbit antisera against PU.l (gift of R. Maki, Cancer Research Center, La Jolla Cancer Research Foundation, CA) was added to these reactions, both complexes were supershifted to a new identical position (Fig. 4, lanes 3,5). Finally, methylation interference footprinting showed that both proteins contacted the same $\mathrm{A}$ and $\mathrm{G}$ residues at the $J B$ site (Fig. 3A).

Further evidence for the identity of the NF-JB and PU.1 proteins was obtained by use of the proteolytic clipping bandshift assay (PCBA) (Schreiber et al. 1988). For these experiments, each factor was incubated with labeled JB oligonucleotide under standard bandshift conditions, protease was added in increasing amounts, and the DNA-binding fragments generated were resolved by electrophoresis on nondenaturing gels. As the trypsin and chymotrypsin data in Figure 5 illustrate, the patterns of PU.1 and NF-JB proteolysis were indistinguishable. Thus, with both proteins, trypsin treatment yielded a single DNA-binding fragment, whereas chymotrypsin treatment produced at least four progressively clipped protein fragments. Moreover, the range in size of the proteolytic fragments indicated that PU.1 and NF-JB shared more than identical DNA-binding domains. Taken together, these results demonstrate that the NFJB protein is Ets-related PU.1 and it will be referred to as such hereafter.

\section{PU.1 recognizes the IB site with relatively high affinity}

Since the JB element contains a novel Ets-binding site, the affinity of PU.1 for that site was compared with its affinity for other functional PU.1-binding sites. For these measurements, oligonucleotides containing PU.1-binding sites from the J-chain promoter, SV40, and the $\mathrm{k} 3^{\prime}$ enhancer were ${ }^{32} \mathrm{P}$-end-labeled to equal specific activity and incubated with equal amounts of in vitro-translated PU.1. The complexes formed were then resolved on a nondenaturing polyacrylamide gel (Fig. 6), and the percentage of each oligonucleotide bound to PU.1 was determined by measuring the ${ }^{32} \mathrm{P}$ content of gel slices containing the PU.1 complexed and free probe. The NFAT site of the IL-2 enhancer that binds another Ets-related protein, Elf-1, was used as a negative control (Thompson et al. 1992). The results indicated that PU.1 binds the

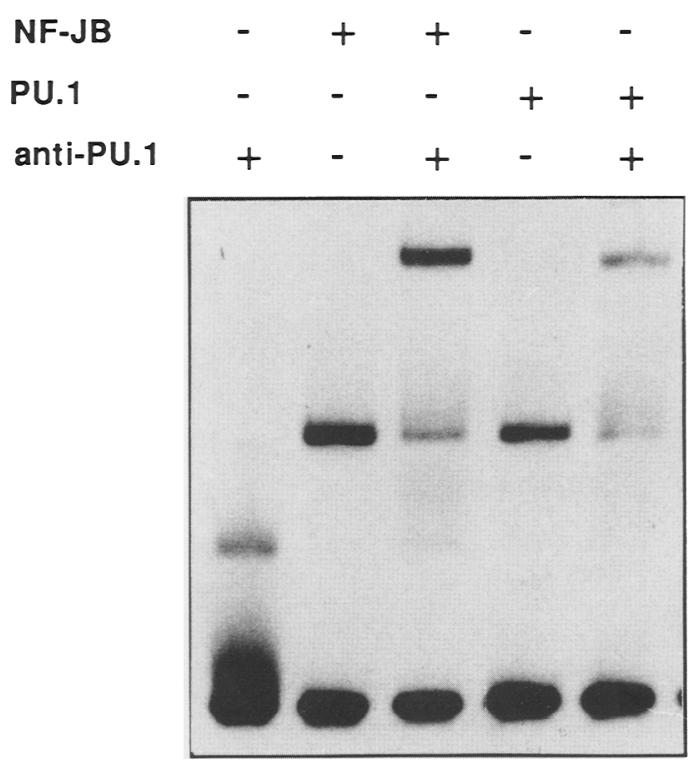

Figure 4. Identical DNA-binding properties of NF-JB and PU.1. Gel mobility shift assays of purified NF-JB and in vitro-translated PU.1 in the presence or absence of rabbit anti-PU.1 antibody (gift of R. Maki). The end-labeled probe was a 28-bp JB oligonucleotide, 5'-CTAGATTTTAAGAAAGCAGAAGCAGCAT $-3^{\prime}$ encoding bp -64 to -42 . 

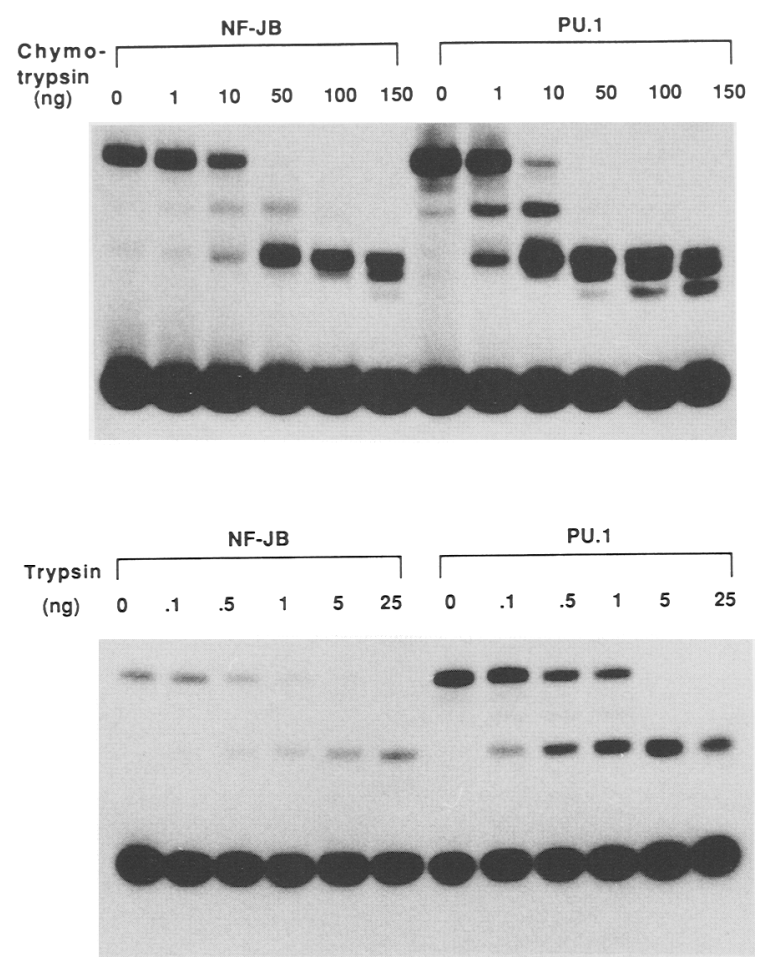

Figure 5. Identical proteolytic digestion patterns of NF-JB and PU.1. Gel mobility shift assays of purified NF-JB and in vitrotranslated PU.1 preincubated with the end-labeled JB oligonucleotide described in the legend to Fig. 4 and then incubated for an additional $10 \mathrm{~min}$ with the indicated amount of chymotrypsin or trypsin.

purine-rich JB element with relatively high affinity, despite the fact that the element lacks the GGA core. Thus, the amount of PU.1 bound to the JB element was three times that bound to the $\mathrm{KE} 3$ ' site, but only onethird that bound to the SV40 site (Fig. 6). These findings are consistent with previous determinations showing that PU.1-bound more strongly to the SV40 PU.1-binding site than to the $\mathrm{kE} 3$ ' site (Pongubala et al. 1992).

\section{PU.1 binds the IB element only as a monomer}

Previous analyses of mutant JB oligonucleotides had indicated that PU.1 did not form homo- or heterodimers nor did it require such interactions for recognition of the JB element. The evidence was based on gel mobility shift assays showing that substitutions in bases in contact with PU.1 abolished the formation of a single band corresponding to a PU.1 monomer-probe complex and left other more slowly migrating bands intact (Lansford et al. 1992). Further evidence that only a single species of PU.1 binds the JB element was obtained by comparing the binding patterns of endogenous PU.1 to JB and $\kappa 3^{\prime}$ enhancer probes (Fig. 7). Recently, Pongubala et al. (1992, 1993) reported that PU.1 interacts with a B-cell-specific factor, NF-EM5, bound to an adjacent downstream site, and the interaction is necessary for $\kappa 3^{\prime}$ enhancer activity. To detect the formation of such complexes, gel mo- bility shift assays were performed with nuclear extracts from S194 myeloma cells that were known to contain both PU.1 and NF-EM5. With the JB probe, a single complex corresponding to the binding of a PU.1 monomer was observed (Fig. 7, lane 1); a similar pattern was obtained with the SV40 control probe (Fig. 7, lane 2). With the $\mathrm{KE}^{\prime}$ ' probe, however, two complexes were formed, a small amount migrating as a monomer of PU.1 and a large amount of more slowly migrating material, presumably a heterodimer of PU.1 and NF-EM5. The PU.1containing complexes were positively identified by use of a rabbit anti-PU.1 serum prepared as described in $\mathrm{Ma}-$ terials and methods. This antibody, in contrast to the reagent used in the experiments described in Figure 4, abrogated DNA binding by PU.1 so that the major band seen with the JB and SV40 probes and both the monomer and larger complexes seen with the $\mathrm{KE}^{3}$ ' probe were abolished (Fig. 7, lanes 4-6). Although longer exposure of the gel revealed additional slower migrating species with the JB probe, these complexes did not react with the antiPU.1 antibody.

\section{PU.1 trans-activation of the J-chain JB promoter element}

PU.l was previously assigned an activator role in J-chain gene transcription based on mutational analyses of the JB element (Lansford et al. 1992). This assignment was sup-

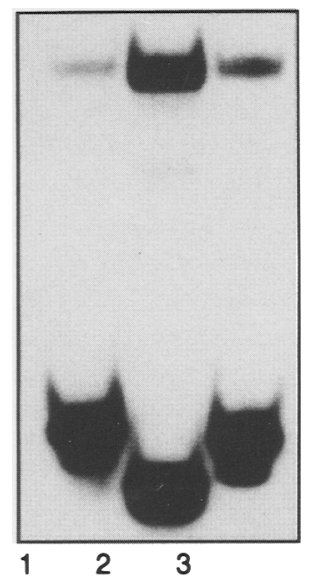

Relative PU.1 binding

1) Ig $\times 3$ ' enhancer

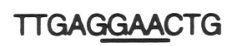

2) SV40 Pu box

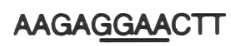

3) $\mathrm{J}$ chain promoter

AAGCAGAAGCA

1.0

4) IL-2 enhancer

AAGAGGAAAAT

0

Figure 6. Relative binding affinity of PU.1 for different PU.1binding-sites. Gel mobility shift assays of in vitro-translated PU.1 incubated with oligonucleotides end-labeled to equal specific activity that contained the $\mathrm{KE}^{\prime}$-, SV40-, and JB PU.1-binding sites (lanes 1,2, and 3, respectively). Relative PU.1 binding was determined by excising gel slices containing the bound and free probes and measuring their ${ }^{32} \mathrm{P}$ content. 


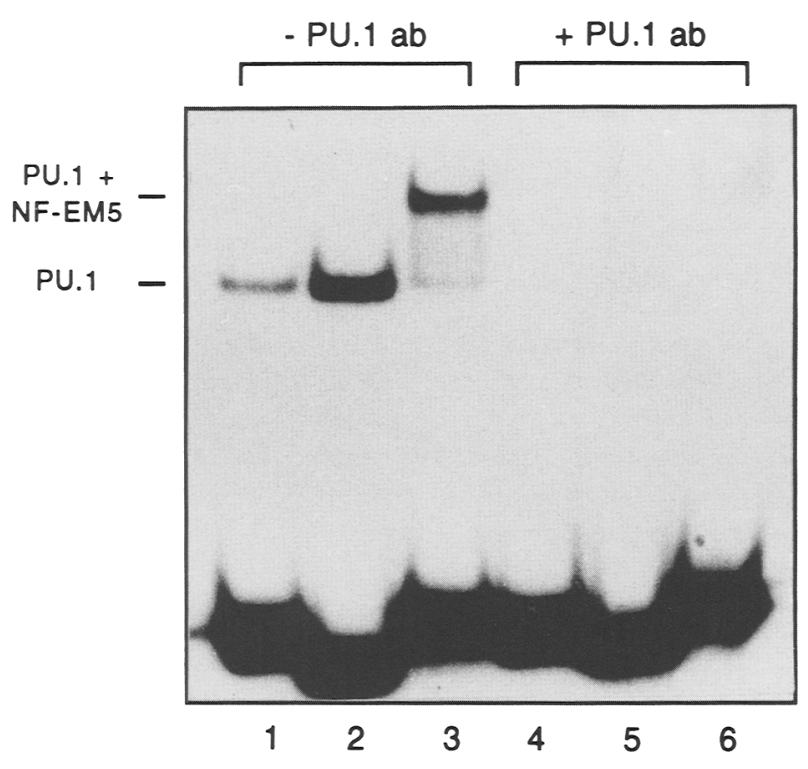

Figure 7. PU.1 binds the JB element as a monomer. Gel mobility shift assays of S194 plasmacytoma nuclear extract incubated with end-labeled probes in the presence and absence of anti-PU.1 rabbit sera (lanes 1-3) and lanes 4-6, respectively. Binding assays were performed with JB (lanes 1,4), SV40 (lanes 2,5 ) and $\kappa E 3^{\prime}$ (lanes 3,6) probes.

ported by transient transfection experiments that assayed the ability of PU.1 to mediate transcriptional activation through the JB element. The effector plasmid for these assays was made by cloning PU.l cDNA into the pcDNA-1 expression vector that carries the cytomegalovirus (CMV) promoter and enhancer. Reporter plasmids were constructed by inserting four copies of wild-type or mutant JB oligonucleotide in the J21 vector upstream of a minimal c-fos promoter and the CAT gene (Lenardo et al. 1987). Although the c-fos-linked system was less sensitive to JB regulation than the $\gamma$-fibrinogen linked system used in previous analyses (Lansford et al. 1992), it had the advantage of a detectable basal chloramphenicol acetyltransferase (CAT) activity in both J-chain-negative and J-chain-positive cells and, thus, allowed comparison of the results from the different lines. Various combinations of the reporter and effector plasmids were then transfected into HeLa cells that lack PU. 1 and into PD31 pre-B cells and S194 myeloma cells that express PU.1.

Overexpression of PU.1 was found to trans-activate the target CAT reporter gene in all three cell types examined. Thus, in J-chain-negative HeLa and PD31 cells, the transfected PU.1 protein overrode the repressive action of the JB sequences in the reporter construct and stimulated increases in the CAT activity of 14- and 13.5fold, respectively (Fig. 8A; PD31 data not shown). In J-chain-expressing S194 cells, on the other hand, the transfected PU.1 protein amplified the stimulatory action of the JB tetramer in the reporter construct by inducing an additional sixfold increase in CAT expression (Fig. 8B). In each cell line, the trans-activation was specific; no increase in CAT activity was observed with target constructs that lacked $\mathrm{JB}$ inserts or contained mutant inserts (Fig. 8B). These data demonstrated that the JB element is a target for transcriptional activation by PU.1 and an exception to the requirement of a core 5'GGA-3' sequence for Ets domain protein binding.

\section{Identification of PU.1 activation domain}

The sequences responsible for the activating function of PU.1 were defined by deletion analyses. Plasmids were constructed that expressed a series of PU.1 proteins truncated from the amino terminus (Fig. 9). The choice of amino-terminal truncations was based on earlier studies that had delineated three structural features of the protein: an acidic amino-terminal sequence (residues 1-118) presumed to encode an activation domain, a basic carboxy-terminal sequence known to contain the DNAbinding domain (167-255), and a connecting PEST sequence (119-160) that has been implicated as a site of protein-protein interaction (Klemsz et al. 1990; Pongubala et al. 1992, 1993). The effect of the deletions was then measured by transfecting the expression plasmids into $\mathrm{S} 194$ cells along with a reporter plasmid containing
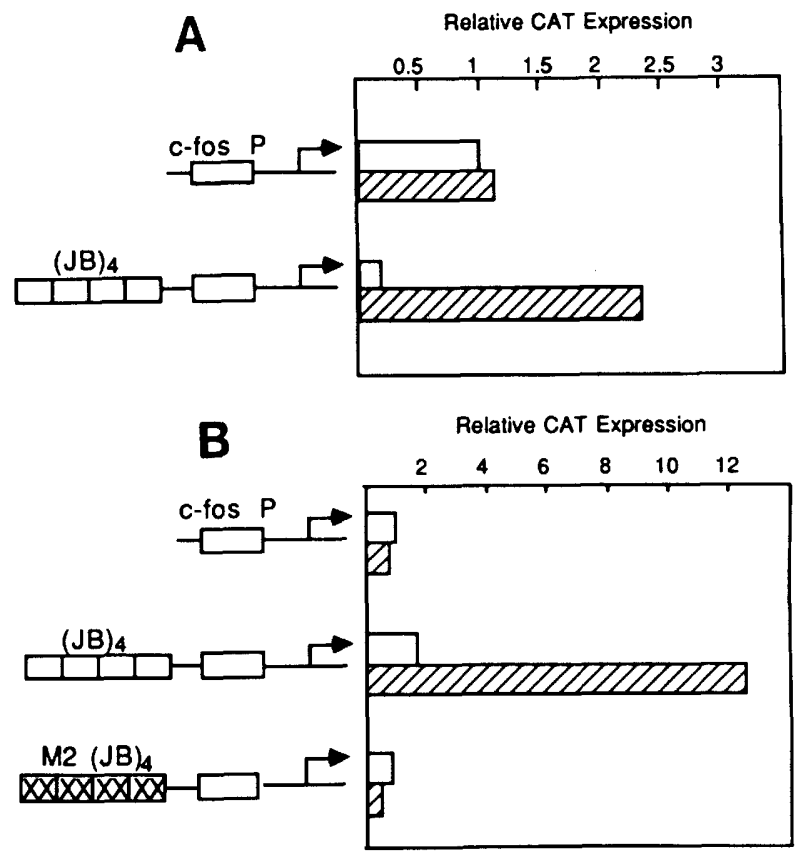

Figure 8. PU.1 trans-activation of the JB element. PU.1 was assayed for its ability to mediate transcription through the JB element by cotransfecting into J-chain-negative HeLa cells $(A)$ and J-chain-positive S194 cells $(B)$ an expression plasmid containing PU. 1 cDNA and a c-fos reporter construct containing four copies of wild-type or mutant JB oligomer. (Open box) -PU.1; (hatched box) + PU.1. Relative CAT activities were determined from the average of at least three independent duplicate determinations; in all cases, the S.E.M. was $\pm 20 \%$. Absolute percentage conversions of chloramphenicol to acetylated forms were $0.0153 \pm 0.005$ and $0.139 \pm 0.018 / \mu \mathrm{g}$ protein per $0.1 \mathrm{mCi}$ $\left[{ }^{14} \mathrm{C}\right]$ chloramphenicol for the c-fos construct in HeLa and S194 cells, respectively. 
A

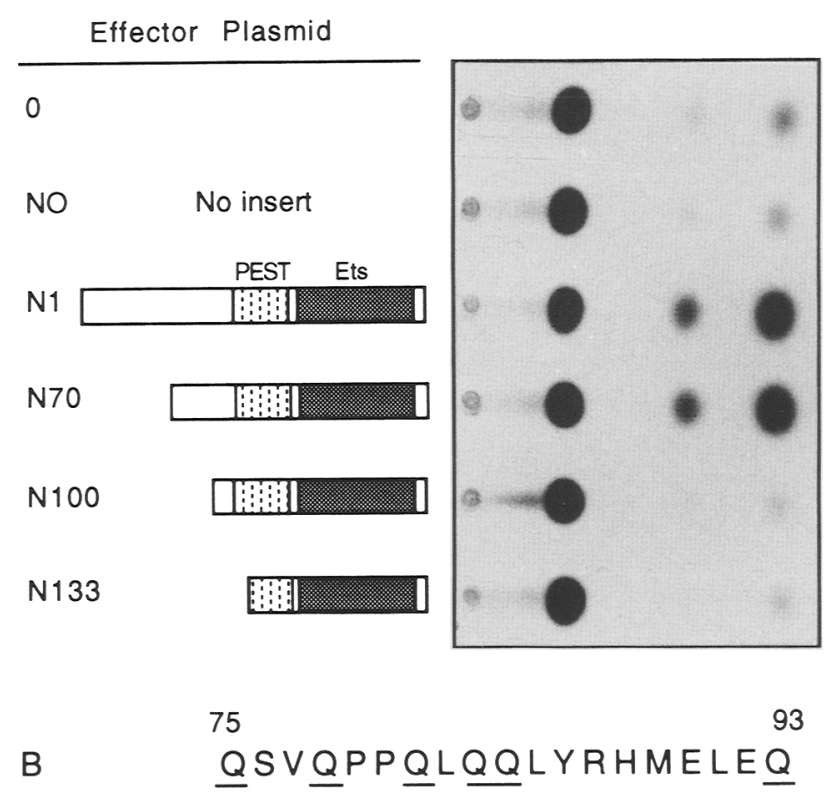

Relative CAT

Activity

1.0 Figure 9. Identification of a trans-activating function in the amino-terminal portion of PU.1. $(A)$ Effector plasmids expressing no PU.1, wild-type $0.95 \pm 0.23$ PU.1, and various PU.1 mutants truncated at the amino terminus were transfected into J-chain positive $\$ 194$ cells, along with a reporter plasmid containing four copies of the JB-binding site upstream of a minimal $\gamma$-fibrinogen promoter and the CAT gene. The structure of the PU.1 deletion mutants is diagramed at left, an autoradiograph of a representative CAT assay is shown in the middle, and the relative CAT activities from four independent duplicate determinations are listed at right. S.E.M. $=$ standard error of the mean. Absolute percentage conversion of chloramphenicol to acetylated forms by the $\gamma$-fibrinogen construct was $0.045 \pm 0.0136 / \mu \mathrm{g}$ of protein per $0.1 \mathrm{mCi}$ $\left[{ }^{14} \mathrm{C}\right]$ chloramphenicol. $(B)$ The amino acid sequence showing the putative transactivating domain. The glutamine $(\mathrm{Q})$ residues are underlined. four copies of the JB-binding sites upstream of a minimal $\gamma$-fibrinogen promoter and the CAT gene (Lansford et al. 1992).

The results of the deletion analyses were clear-cut (Fig. 9A); removal of the first 70 amino acids of PU.1 had no significant effect on its ability to trans-activate through the JB element. Removal of the next 30 amino acids, however, decreased transcriptional activation to the background level and deletion of yet another 33 amino acids to a level below background, indicating that the PU. $1_{133-272}$ protein may have acted as a dominant negative protein to suppress the activity of the endogenous intact PU.1. The lack of activity by the PU. $1_{100-272}$ and PU. $1_{133-272}$ plasmids could not be attributed to lack of expression because gel mobility shift assays showed that comparable amounts of DNA-binding protein were produced by the four PU.1 constructs (data not shown). Thus, the sequence encompassing amino acids 70 and 100 was identified as critical for PU.1 trans-activating function. Moreover, the high glutamine content of the sequence was consistent with such a function; for example, glutamine accounts for $31 \%$ of the residues between amino acids 75 and 93 (Klemsz et al. 1990; Fig. 9B). Stretches rich in glutamine occur in many established transcription factors and, in the case of Spl, have been shown to contribute to transcriptional activation (Courey and Tjian 1988; Mitchell and Tjian 1989).

\section{A PU.1 dominant negative mutant blocks PU.1 regulation of the I-chain gene promoter}

To obtain definitive evidence for the in vivo role of PU.1 in J-chain gene transcription, we took advantage of the finding that the PU. $1_{133-272}$ mutant appeared to act as a dominant negative mutant and suppress the activity of endogenously synthesized PU.1 (Fig. 9). For these assays, the vector expressing the N133 mutant was transfected into $\mathrm{S} 194$ cells along with a CAT reporter gene containing $1.24 \mathrm{~kb}$ of $\mathrm{J}$-chain promoter sequence upstream and $1.0 \mathrm{~kb}$ of $\mu$ heavy chain enhancer sequence downstream (Lansford et al. 1992). Control transfections included expression vectors with no insert or an intact PU.1 insert and a reporter construct in which the J-chain promoter sequence was replaced with the minimal $\gamma$-fibrinogen promoter.

As shown in Figure 10, overexpression of the intact PU.1 had little effect on the activity of the J-chain promoter construct; the level of CAT expression was essentially equivalent to that obtained when just the pcDNA-1 vector was cotransfected. The failure to observe any significant positive regulatory activity suggested that enough endogenous PU.1 was present in the S194 cells to trans-activate through the single PU.1 site in the J-chain reporter construct. Such an explanation was consistent with the results from cotransfection assays using the JB element as the target sequence (Fig. 8B); multiple JB elements were required to observe an enhancement of activity by the transfected PU.1 expression plasmid.

In contrast to the results obtained with intact PU.1, overexpression of the N133 PU.1 mutant drastically suppressed the transcriptional activity of the J-chain reporter construct. Control experiments showed that the suppression was effected by the competitive binding of the N133 mutant protein to the PU.1 site in the J-chain promoter. Thus, overexpression of the $\mathrm{N} 133$ protein failed to suppress and, in fact, slightly enhanced the activity of a reporter construct that differed only in the substitution of a $\gamma$-fibrinogen promoter for the J-chain promoter sequence (Fig. 10). Moreover, the reduction in 


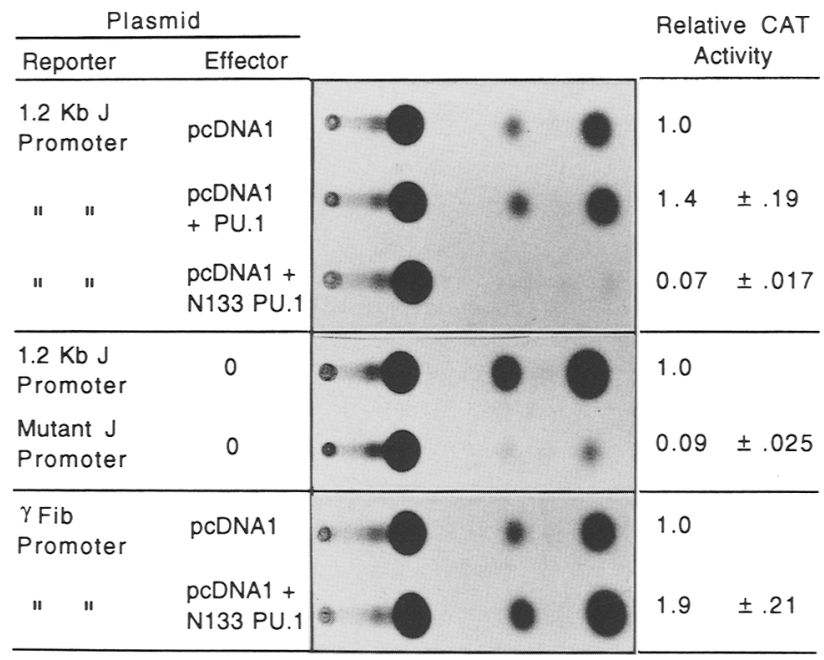

Figure 10. A PU.1 dominant negative blocks endogeneous PU.1 activation of the J-chain promoter. Reporter constructs containing as targets either the $1.24-\mathrm{kb}$ J-chain promoter or the minimal $\gamma$-fibrinogen promoter were cotransfected with effector plasmids expressing no PU.1, intact PU.1, or the truncated PU.1 ${ }_{133-272}$ mutant (N133). The 1.24-kb mutant J-chain reporter construct contained the same $2 \mathrm{bp}$ as the M2J2 oligonucleotide (see Materials and methods). An autoradiograph of a representative CAT assay is shown in the middle, and the relative CAT activities from three independent duplicate determinations are listed at right. Absolute percentage conversion of chloramphenicol to acetylated forms by the $1.24-\mathrm{kb}$ J-chain promoter construct cotransfected with pcDNAl was $0.33 \pm 0.060$; by the 1.24 -kb J-chain promoter construct without effector plasmid, $0.69 \pm 0.031$; and by the $\gamma$-fibrinogen promoter construct, $1.4 \pm 0.20 / \mu \mathrm{g}$ of protein per $0.1 \mathrm{mCi}\left[{ }^{14} \mathrm{C}\right]$ chloramphenicol.

J-chain promoter activity induced by the $\mathrm{N} 133$ dominant negative mutant was comparable to that observed when a 2-bp substitution (M2) was made in the single PU.1 site in the 1.24-kb J-chain promoter sequence (Fig. 10; Lansford et al. 1992); the losses were 14- and 11-fold, respectively. These data indicated that the N133 mutant and the site-specific mutations suppressed promoter activity by the same mechanism, that is, by preventing the binding of endogenous PU. 1 to the JB element. The alternative interpretation of the data-that a nuclear factor other than PU.1 was prevented from binding to the JB site-seems highly unlikely. In gel mobility shift assays with $\mathrm{S} 194$ nuclear extracts the major JB-binding protein was identified as PU.1 (Fig. 7), and it was the only complex abolished by the 2-bp substitution in the JB site (Lansford et al. 1992).

\section{Discussion}

In this study we purified a B-cell nuclear protein, NF-JB, that interacts with a major promoter element in the $\mathrm{J}$-chain gene. Molecular and biochemical characterization of the purified protein revealed that NF-JB is identical to the Ets oncoprotein PU.1, which is expressed exclusively in B-lymphoid cells and macrophages
(Klemsz et al. 1990). Like other members of the Ets oncoprotein family (for review, see Macleod et al. 1992), PU.1 has been a transcription factor in search of a normal, cellular function. Here, we establish that one of its functions is to regulate a critical event in a B-cell immune response, the expression of the J-chain gene. The evidence is based on the following observations. First, PU.1 recognizes the JB positive regulatory motif in the J-chain promoter and binds to this element with relatively strong affinity (Figs. 1 and 6). Second, PU.1 transactivates reporter constructs containing the $\mathrm{JB}$ element; in J-chain-negative cells it overrides the action of the endogenous repressor and in J-chain-positive cells it adds to the stimulatory effect of the endogenous PU.1 (Fig. 8). Finally, a dominant negative mutant of PU.1 suppresses the transcriptional activity of the $1.2-\mathrm{kb}$ J-chain promoter construct, and the amount of suppression is equivalent to that obtained by mutations in the $1.2 \mathrm{~kb}$ sequence that prevents PU.1 binding (Fig. 10).

The recognition of the JB promoter element by the Ets-related PU.1 has considerable implications for defining the Ets family of DNA-binding proteins. To date, the major criteria for family membership has been a conserved domain of $\sim 85$ amino acids that recognizes a purine-rich motif with a central invariant GGA-trinucleotide (Karim et al. 1990; Macleod et al. 1992; Nye et al. 1992). The purine-rich JB element, however, lacks the GGA core and yet it is bound by PU.1 with higher affinity than sequences, such as the $\mathrm{KE} 3$ ' motif, which contain the consensus GGA. The JB-PU.1 interaction may represent a rare exception to the Ets-binding site definition; the PU.1-binding domain has the least conserved sequence in the Ets family (Karim et al. 1990) and, as a result, may have a distinct DNA-binding specificity. This explanation is consistent with the mutational analyses of the Ets-1-binding site. Changing the GGA consensus to the AGA sequence found in the JB element abolished both Ets-1 binding and Ets-1-mediated transcription (Wasylyk et al. 1990). Alternatively, however, the PU.1-JB element interaction may indicate that the Ets-binding sites constitute a degenerative series, and thus the repertoire of sites and reactive Ets proteins is much larger than would be expected from surveys using the consensus GGA core sequence.

The trans-activation of the JB element by PU.1 also has implications for understanding the regulatory function of the Ets proteins. There is considerable evidence that PU.1 does not require the cooperation of a second nuclear factor for this function. First, assays of PU.1 binding using either mutant JB probes (Lansford et al. 1992) or anti-PU.1-specific antibody failed to reveal any PU.1-protein interactions. Second, PU.1 was able to trans-activate through JB elements that contained only 3-bp and 6-bp adjoining sequences, suggesting that flanking sequences have a minimal effect on PU.1-trans-activating function (data not shown). Third, the amino-terminal region of PU.1 has been shown recently to bind the TFIID subunit of RNA polymerase II (Hagemeier et al. 1993), a finding consistent with our demonstration that the activating function of PU.1 is located in a glu- 
tamine-rich region involving amino acids 70-100. A similar case can be made for PU.1 alone being capable of mediating transcriptional activation through the PU box of SV40 (Klemsz et al. 1990). In the case of the $k 3^{\prime}$ enhancer, however, PU.1 has been shown to recruit the binding of a second B-cell-restricted factor to an adjacent DNA site. The PU.1-NF-EM5 interaction depends on the phosphorylation of PU.1 at Ser-148 and is required both for NF-EM5 binding to DNA and for efficient transactivation of the $\kappa E 3^{\prime}$ element (Pongubala et al. 1993).

Our analyses of PU.1 interaction with the various JB-, SV40-, and KE3'-binding sites suggest that the requirement for a second subunit may depend on the affinity of the Ets domain for the promoter element. PU.1 interaction at relatively strong binding sites, such as SV40 and JB elements, may result in stable complexes that present a glutamine-rich interface for binding to TFIID and/or TFIIB and the subsequent assembly of the multicomponent transcriptional machinery. At weaker sites, such as in the $\kappa 3^{\prime}$ enhancer, the presence of a second factor may help to maintain an appropriate interacting interface, like a three-dimensional jigsaw puzzle (Thompson and McKnight 1992). The correlation observed between PU.1-binding affinity and the requirement for a second factor is supported by studies of several other Ets family members. Thus, the Ets protein GAPB $\alpha$ binds weakly to the GA-rich element of herpes simplex virus (HSV) immediate early (IE) promoters; it interacts, however, with a Notch-related protein, GABP $\beta$, to form tetramers that bind strongly to the same motif (Thompson et al. 1991). Another Ets member, SAP-1, recognizes the serum response element of the c-fos promoter only in combination with the serum response factor (SRF) (Dalton and Treisman 1992).

Using biochemical and in vivo functional assays, we have directly demonstrated that PU.1 is a transcriptional activator of the J chain. How PU.1 contributes to the tissue-specific expression of the $J$ chain is apparent from its tissue distribution. PU.1 expression is limited to B cells and macrophages, and of these two cell types, only B cells express IL-2 and IL-5 receptors and have been shown to respond to the respective lymphokines. On the other hand, how PU.1 contributes to the change in function of the JB element and, thus, to the developmentspecific expression of J chain is not clear. Northern analysis revealed that the level of PU.1 message remains constant during B-cell development and is not affected by IL-2 stimulation. Analyses of nuclear levels of PU.1 protein gave similar results. Moreover, no changes have yet been observed in PU.1 structure that correlate with J-chain gene activation (data not shown). The simplest interpretation of these findings is that PU.1 is prevented from functioning in the antigen-independent stages of B-cell development because the JB site is inaccessible. Some change occurs in the site during a primary immune response, for example, the release of a repressor or an opening of a DNA structure, that allows PU.1 to bind and serve an activator function. It seems likely, therefore, that the concerted action of several factors including PU.1 will be required to account for the cytokine inducibility and developmental specificity of $J$ chain expression. This issue can be addressed as we identify and characterize additional factors (McFadden and Koshland 1991; Lansford et al. 1992) that are involved in J-chain gene regulation.

\section{Materials and methods \\ Cell culture and transfections}

The myeloma cell line S194 and the nonlymphoid cell line HeLa were grown at $37^{\circ} \mathrm{C}$ under $8 \% \mathrm{CO}_{2}$ in Dulbecco's modified Eagle medium supplemented with $10 \%$ fetal bovine serum, $2 \mathrm{~mm}$ L-glutamine, $50 \mu \mathrm{M}$ 2-mercaptoethanol, $100 \mathrm{U} / \mathrm{ml}$ of penicillin, and $100 \mu \mathrm{g} / \mathrm{ml}$ of streptomycin. The mature B-cell line $\mathrm{K} 46 \mathrm{R}$ and the pre-B-cell line PD31 were maintained in RPMI 1640 medium supplemented as described above.

Transfections of S194, HeLa, and PD31 cells were performed by the DEAE-dextran technique with $10 \mu \mathrm{g}$ of supercoiled test plasmid for $10^{7}$ cells (Grosschedl and Baltimore 1985). Cell extracts were prepared $40-48 \mathrm{hr}$ after transfection and assayed for CAT activity as described previously (Lansford et al. 1992). For the trans-activation assays the total amount of DNA was kept constant by using $5 \mu \mathrm{g}$ of reporter vector and $4 \mu \mathrm{g}$ of expression vector or an equivalent amount of Bluescript $\mathrm{KS}|+|$ II DNA (Strategene). For the dominant-negative transfection assays, 3 $\mu \mathrm{g}$ of reporter vector and $6 \mu \mathrm{g}$ of expression vector or the equivalent amount of Bluescript KS + + II DNA were used.

\section{Oligonucleotides}

The following oligonucleotides were synthesized for use in DNA-binding and in vivo functional assays. The putative core for the ets binding site is in bold print. JB, $5^{\prime}$-CTAGATTTTAAGAAAGCAGAAGCAGCAT-3'; M2JB, 5'-CTAGATTTTAAGAAAGCCTAAGCAGCAT-3'; кE3', 5'-GATCCCTTTGAGGAACTGAAAACAGAACCTG-3'; SV40， 5'-GATCCTGAAAGAGGAACTTGGTA-3'; NFAT', 5'-TCGAAAGAGGAAAATTTGTTTCATACAGAAGGCG-3'.

\section{Purification of NF-JB protein}

Nuclear extracts were prepared from $2 \times 10^{10}$ B-lymphoma K46R cells (Lansford et al. 1992) and dialyzed against buffer $S$ (20 mM HEPES at pH 7.6, 0.1 $\mathrm{M} \mathrm{KCl}, 1 \mathrm{~mm}$ DTT, $0.5 \mathrm{mM}$ PMSF, $0.5 \mathrm{mM} \mathrm{Na} \mathrm{S}_{2} \mathrm{O}_{2}, 10 \mathrm{U} / \mathrm{ml}$ of aprotinin, and $0.5 \mathrm{mg} / \mathrm{ml}$ of leupeptin and pepstatin A) at $4^{\circ} \mathrm{C}$. Approximately $100 \mathrm{mg}$ of extract protein was applied to a $10-\mathrm{ml}$ S-Sepharose fast flow column (Pharmacia) equilibrated with buffer S. Bound protein was eluted with a $170-\mathrm{ml}$ linear gradient from 0.1 to $1.0 \mathrm{M} \mathrm{KCl}$. Fractions containing NF-JB activity, as judged by gel mobility shift assays, were pooled from six S-Sepharose fractionations and diluted to $0.1 \mathrm{M} \mathrm{KCl}$ buffer $\mathrm{Z}$ (buffer S supplemented with $0.05 \%$ lauryldimethyamine oxide (LDAO) (CalBiochem). The material was then applied to six 1-ml DNA-affinity columns (Kadonaga and Tjian 1986) containing the sequence-specific JB oligonucleotide, described above. The bound proteins were eluted with a stepwise gradient of $0.1 \mathrm{M} \mathrm{KCl}$ increments from 0.1 to $1.0 \mathrm{M}$. The fractions with NF-JB activity were diluted to $0.1 \mathrm{M} \mathrm{KCl}$ buffer $\mathrm{Z}$ and applied to three $1-\mathrm{ml} \mathrm{JB}$ affinity columns; the process was then repeated with the use of a single $1-\mathrm{ml} \mathrm{JB}$ affinity column. The final NF-JB product was precipitated with $10 \%$ TCA, dissolved in SDS loading buffer, electrophoresed under reducing conditions on a $10 \%$ SDS-polyacrylamide gel, and visualized by silver staining (Wray et al. 1981). 


\section{Characterization of NF-JB and PU.1 factors}

UV cross-linking experiments were performed as described (Chodosh 1991). The JB oligonucleotide described above was cloned into the $\mathrm{XbaI}$ site of pBluescript $\mathrm{KS}|+| \mathrm{II}$ vector (Strategenel, and the resulting construct was used to prepare the top JB strand. A bottom strand containing 5'-bromo-2'-dUTP (BrdU, Pharmacia LKB) and $\left[{ }^{32} \mathrm{P}\right] \mathrm{dCTP}$ was synthesized from the top strand by the use of M13 universal primer (New England Biolabs) and Klenow enzyme. The BrdU-containing JB probe was isolated from the vector by $\mathrm{XbaI}$ digestion and gel electrophoresis and incubated with purified NF-JB in binding buffer $/ 10$ $\mathrm{mm}$ Tris- $\mathrm{HCl}$ at $\mathrm{pH} 7.5,50 \mathrm{~mm} \mathrm{NaCl}, 1 \mathrm{~mm}$ EDTA, $1 \mathrm{~mm}$ DTT, $5 \%$ glycerol) in the presence or absence of excess cold competitors. The synthetic JB oligonucleotide and a mutant form, $\mathrm{M} 2 J \mathrm{~B}$, were used as specific and nonspecific competitors, respectively. After the samples were exposed to UV light for 30 min, they were analyzed by $10 \%$ SDS-PAGE with ${ }^{14} \mathrm{C}$-labeled protein molecular mass standard (Pharmacia). The gel was treated with ENhance (NEN, DuPont), dried, and examined by autoradiography.

To obtain PU.1 protein for analysis, the pBluescript KS|+|II vector containing the full length PU.1 cDNA (Klemsz et al. 1990) was linearized with BamHI, transcribed in vitro with T3 RNA polymerase (Boehringer Mannheim), and translated in vitro with a rabbit reticulocyte lysate (Promega) according to the manufacturer's suggested protocols.

For gel mobility shift assays, the specific oligonucleotides were end-labeled with $\left[\alpha^{-32} \mathrm{P}\right] \mathrm{dCTP}$ or $\left[\alpha^{-32} \mathrm{P}\right] \mathrm{dATP}$ and Klenow enzyme (Sambrook et al. 1989). The binding reactions were performed as described previously (McFadden and Koshland 1991) with the following modifications. One microliter of purified NF-JB or in vitro-synthesized PU.1 was incubated at $22^{\circ} \mathrm{C}$ for 20 min with $10^{4} \mathrm{cpm}$ of end-labeled JB probe in $20 \mu \mathrm{l}$ of the binding buffer given above. No nonspecific competitor DNA was used for binding reactions with purified NF-JB, whereas $1 \mu \mathrm{g}$ of nonspecific competitor poly[d(I-C)] (Pharmacia) was added to the reactions with in vitro-synthesized PU.l. For the supershift or complex ablation assays, NF-JB and PU.1 were incubated with labeled JB probe as described above, $1 \mu$ l of rabbit anti-PU.1 antiserum was added to each reaction, and the samples were incubated for an additional $10 \mathrm{~min}$. In each case the proteinDNA complexes were separated by electrophoresing the samples on $5 \%$ polyacrylamide gel $(29: 1)$ containing $0.25 \times$ TBE buffer.

Methylation interference footprinting assays were performed by a standard method (Baldwin 1991). Each preparative scale mobility shift binding reaction was 5-fold in NF-JB or PU.1, 5 -fold in poly[d(I-C)] for the PU.1 reactions, and 10-fold in probe. The probe was a 75-bp PstI/HaeIII fragment containing the J-chain promoter sequence -83 to -8 , which was end-labeled on the top or bottom strand.

PCBAs were performed according to the protocol of Schreiber et al. (1988). Purified NF-JB or in vitro-synthesized PU.1 was incubated with end-labeled JB probe under the conditions used for standard gel mobility shift assays. Various concentrations of freshly diluted chymotrypsin or trypsin (Boehringer Mannheim) were added to the binding reactions, and the samples were incubated at $22^{\circ} \mathrm{C}$ for an additional $10 \mathrm{~min}$ and then subjected to electrophoresis.

\section{Plasmid Constructions}

For the cotransfection assays, a PU.1 expression plasmid was prepared by subcloning the full-length $\mathrm{cDNA}$ into the pcDNAl vector in the HindIII-BamHI polylinker sites directly $3^{\prime}$ of the
CMV promoter and enhancer (Invitrogen). Plasmids expressing amino-terminal deletion mutants were constructed by a twostep cloning procedure: First, restriction fragments of PU.1 were cloned into the expression vector pBS-ATG in the polylinker located downstream of a translation initiation site /Clerc et al. 1988); thus, $\triangle$ PU.1 (70-272) was made by inserting the XmnIEcoRI fragment of PU.1 into the polylinker SmaI-EcoRI sites of pBS-ATG, $\triangle$ PU.1 (100-272) by inserting the NcoI-EcoRI fragment, and $\triangle$ PU.1 (133-272) by inserting the SacI-EcoRI fragment into the respective polylinker sites. Each $\triangle P U .1$ sequence, along with the upstream translation initiation site, was then removed from the pBS-ATG vector and cloned into the polylinker HindIII-EcoRI sites of the pcDNAl eukaryotic expression vector. The reporter constructs for these experiments were made by cloning four copies of the JB oligonucleotide into (1) the J21 plasmid upstream of the minimal c-fos promoter and the CAT gene (Lenardo et al. 1987), or (2) the p 442 Cassl vector upstream of a truncated $\gamma$-fibrinogen promoter and the CAT gene (Durand et al. 1988; Lansford et al. 1992). The reporter constructs used for the dominant-negative transfections have been described previously (Lansford et al. 1992); they contained either a $1.24-\mathrm{kb}$ J-chain promoter sequence or the truncated $\gamma$-fibrinogen promoter sequence upstream of the CAT gene and a $1.0-\mathrm{kb} \mu$ heavy chain enhancer sequence downstream.

\section{Preparation of anti-PU.1 antibody}

The entire coding region of PU.1 was excised with EcoRI from pBluescript $\mathrm{KS}|+| \mathrm{II}$ and cloned into EcoRI site of pMal-cRI (New England Biolabs). The maltose-binding protein (MBP)PU.l fusion protein was synthesized and purified from TBI Escherichia coli strain according to the manufacturer's suggestions. Rabbits were injected subcutaneously with $250 \mu \mathrm{g}$ of MBP-PU.1 fusion protein initially in complete Freund's adjuvant and subsequently in incomplete Freund's adjuvants. Rabbit sera were assayed for PU.1-specific antibodies by immunoprecipitation and by gel mobility shift assays of their ability to recognize DNA bound PU.1.

\section{Acknowledgments}

We express our appreciation to Drs. A. Winoto and K. Johnson for stimulating and helpful discussions. We also thank Dr. R. Maki for his generous gift of PU.1 cDNA and rabbit anti-PU.1 antisera used in Figure 4 and Ms. J. Fujita for her considerable help in preparing nuclear extracts. This work was supported by grant AI 07079 from the National Institute of Allergy and Infectious Diseases.

The publication costs of this article were defrayed in part by payment of page charges. This article must therefore be hereby marked "advertisement" in accordance with 18 USC section 1734 solely to indicate this fact.

\section{References}

Baldwin, A.S. 1991. DNA-protein interactions. In Current protocols in molecular biology (ed. F.M. Ausubel, R. Brent, R.E. Kingston, D.D. Moore, J.G. Seidman, J.A. Smith, and K. Struhl), vol. 2, pp. 12.3.1-12.3.4. (Chap. 12). Greene Publishing Associates, Brooklyn, New York.

Blackman, M., M.A. Tigges, M.E. Minie, and M.E. Koshland. 1986. A model system for peptide hormone action in differentiation: Interleukin 2 induces a B lymphoma to transcribe the J chain gene. Cell 47: 609-617. 
Bosselut, R., J.F. Duvall, A. Gegonne, M. Bailly, A. Hemar, J. Brady, and J. Ghysdael. 1990. The product of the c-ets-1 proto-oncogene and the related Ets 2 protein act as transcriptional activators of the long terminal repeat of human $T$ cell leukemia virus HTLV-1. EMBO J. 9: 3137-3144.

Chodosh, L.A. 1991. Chap. 12. DNA-protein interactions. In Current protocols in molecular biology (ed. F.M. Ausubel, R. Brent, R.E. Kingston, D.D. Moore, J.G. Seidman, J.A. Smith, and K. Struhl), vol. 2, pp. 12.5.1-.2.5.6 (Chap. 12). Greene Publishing Associates, Brooklyn, New York.

Clerc, R.G., L.M. Cortcoran, J.H. LeBowitz, D. Baltimore, and P.A. Sharp. 1988. The B-cell-specific Oct-2 protein contains POU box and homeo box domains. Genes \& Dev. 2: 1570 1581.

Courey, A. and R. Tjian. 1988. Analysis of Spl in vivo reveals multiple transcriptional domains, including a novel glutamine-rich activation motif. Cell 55: 887-898.

Dalton, S. and R. Treisman. 1992. Characterization of SAP-1, a protein recruited by serum responsive factor to the c-fos serum responsive element. Cell 68: 597-612.

Durand, D.B., J.-P. Shaw, M.R. Bush, R.E. Replogie, R. Belagie, and G.R. Crabtree. 1988. Characterization of antigen receptor response elements within the interleukin-2 enhancer. Mol. Cell. Biol. 8: 1717-1724.

Goebl, M.G. 1990. The PU.1 transcription factor is the product of the putative oncogene Spi-1. Cell 61: 1165-1166.

Grosschedl, R. and D. Baltimore. 1985. Cell-type specificity of immunoglobulin gene expression is regulated by at least three DNA sequence elements. Cell 41: 885-897.

Hagemeier, C., A.J. Bannister, A. Cook, and T. Kouzarides. 1993. The activation domain of transcription factor PU.1 binds the retinoblastoma $(\mathrm{RB})$ protein and the transcription factor TFIID in vitro: RB shows sequence similarity to TFIID and TFIIB. Proc. Natl. Acad. Sci. 90: 1580-1584.

Kadonaga, J. and R. Tjian. 1986. Affinity purification of sequence specific DNA binding proteins. Proc. Natl. Acad. Sci. 83: $5889-5893$.

Karim, F.D., L.D. Urness, C.S. Thummel, M.J. Klemsz, S.R. McKercher, A. Celada, C. van Beveren, R.A. Maki, C.V. Gunther, J.A. Nye, and B.J. Graves. 1990. The ETS-domain: A new DNA-binding motif that recognizes a purine rich core DNA sequence. Genes \& Dev. 4: 1451-1453.

Klemsz, M.J., S.R. McKercher, A. Celada, C. van Beveren, and R.A. Maki. 1990. The macrophage and B cell-specific transcription factor PU.1 is related to the ets oncogene. Cell 61: 113-124.

Koshland, M.E. 1985. The coming of age of the immunoglobulin J chain. Annu. Rev. Immunol. 3: 425-453.

Lansford, R.D., H.J. McFadden, S.T. Siu, J.S. Cox, G.M. Cann, and M.E. Koshland. 1992. A promoter element that exerts positive and negative control of the IL-2 responsive J chain gene. Proc. Nat1. Acad. Sci. 89: 5966-5970.

Lenardo, M., J.W. Pierce, and D. Baltimore. 1987. Protein-binding sites in Ig gene enhancers determine transcriptional activity and inducibility. Science 236: 1573-1577.

Macleod, K., D. Leprince, and D. Stehelin. 1992. The ets gene family. TIBS 17: 251-256.

Matsui, K., K. Nakanishi, D.I. Cohen, T. Hada, J.-I. Furuyama, T. Hamaoka, and K. Higashino. 1989. B cell response pathways regulated by IL- 5 and IL-2. Secretory $\mu \mathrm{H}$ chain mRNA and $J$ chain mRNA expression are separately controlled events. I. Immunol. 142: 2918-2923.

McFadden, H.J. and M.E. Koshland. 1991. Interleuken 2- and interleuken 5 -induced changes in the binding of regulatory factors to the J-chain gene promoter. Proc. Natl. Acad. Sci. 88: 11027-11031.
Minie, M.E. and M.E. Koshland. 1986. Accessibility of the promoter sequence in the J-chain gene is regulated by chromatin changes during B-cell differentiation. Mol. Cell. Biol. 6: 4031-4038.

Mitchell, P. and R. Tjian. 1989. Transcriptional regulation in mammalian cells by sequence-specific DNA binding proteins. Science 245: 371-378.

Moreau-Gachelin, F., A. Tavitian, and P. Tambourin. 1988. Spi-1 is a putative oncogene in virally induced murine erythroleukemias. Nature 331: 277-280.

Nakanishi, K., D.I. Cohen, M. Blackman, E. Nielsen, J. Ohara, T. Hamaoka, M.E. Koshland, and W.E. Paul. 1984. Ig RNA expression in normal B cells stimulated with anti-IgM antibody and $\mathrm{T}$ cell-derived growth and differentiation factors. $J$. Exp. Med. 160: 1736-1751.

Nye, J.A., J.M. Petersen, C.V. Gunther, M.D. Jonsen, and B.J. Graves. 1992. Interaction of murine Ets-1 with GGA-binding sites establishes the ETS domain as a new DNA-binding motif. Genes \& Dev. 6: 975-990.

Pettersson, M. and W. Schaffner. 1987. A purine-rich DNA sequence motif present in SV40 and lymphotropic papovavirus binds a lymphoid-specific factor and contributes to enhancer activity in lymphoid cells. Genes \& Dev. 1: 962-972.

Pongubala, J.R., S. Nagulapalli, M.J. Klemsz, S.R. McKercher, R.A. Maki, and M.L. Atchison. 1992. PU.1 recruits a second nuclear factor to a site important for immunoglobulin $\kappa 3^{\prime}$ enhancer activity. Mol. Cell. Biol. 12: 368-378.

Pongubala, J.R., C. van Beveren, S. Nagulapali, M.J. Klemsz, S.R. McKercher, R.A. Maki, and M.L. Atchison. 1993. Effect of PU.1 phosphorylation on interaction with NF-EM5 and transcription activation. Science 259: 1622-1625.

Sambrook, J., E.F. Fritsch, and T. Maniatis. 1989. Molecular cloning: A laboratory manual. Cold Spring Harbor Laboratory Press, Cold Spring Harbor, New York.

Schreiber, E., P. Matthias, M.M. Muller, and W. Schaffner. 1988. Identification of a novel lymphoid specific octamer binding protein (OTF-2B) by proteolytic clipping bandshift assay (PCBA). EMBO 1. 7: 4221-4229.

Staudt, L.M. and M.J. Lenardo. 1991. Immunoglobulin gene transcription. Annu. Rev. Immunol. 9: 373-398.

Thompson, C.B., C.-I. Wang, I-C. Ho, P.R. Bohjanen, B. Petryniak, C.H. June, S. Miesfeldt, L. Zhang, G.J. Nabel, B. Karpinski, and J.M. Leiden. 1992. Cis-acting sequences required for inducible Interleukin-2 enhancer function bind a novel Etsrelated protein, Elf-1. Mol. Cell. Biol. 12: 1043-1053.

Thompson, C.C. and S.L. McKnight. 1992. Anatomy of an enhancer. Trend Genet. 8: 232-236.

Thompson, C.C., T.A. Brown, and S.L. McKnight. 1991. Convergence of ets- and notch-related structural motifs in a heteromeric DNA-binding complex. Science 253: 762-768.

Wang, C.-Y., B. Petryniak, I-C. Ho, C.B. Thompson, and J.M. Leiden. 1992. Evolutionarily conserved Ets family members display distinct DNA binding specificities. /. Exp. Med. 175: 1391-1399.

Wasylyk, B., C. Wasylyk, P. Flores, A. Begue, D. Leprince, and D. Stehelin. 1990. The c-ets proto-oncogenes encode transcription factors that cooperate with c-Fos and c-Jun for transcription activation. Nature 346: 191-193.

Wray, W., T. Boulikas, V.P. Wray, and R. Hancock. 1981. Silver staining of proteins in polyacrylamide gels. Anal. Biochem. 118: 197-203.

Xin, J.-H., A. Cowie., P. Lachane, and J.A. Hassell. 1992. Molecular cloning and characterization of PEA3, a new member of the ETS oncogene family that is differentially expressed in mouse embryonic cell. Genes \& Dev. 6: 481-496. 


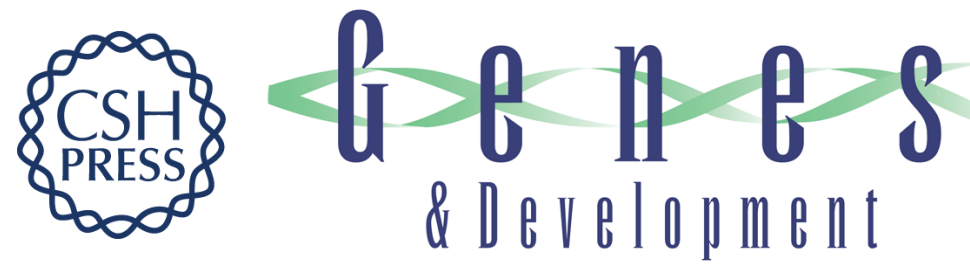

\section{Ets-related protein PU.1 regulates expression of the immunoglobulin J-chain gene through a novel Ets-binding element.}

M K Shin and M E Koshland

Genes Dev. 1993, 7:

Access the most recent version at doi:10.1101/gad.7.10.2006

References This article cites 35 articles, 19 of which can be accessed free at:

http://genesdev.cshlp.org/content/7/10/2006.full.html\#ref-list-1

License

Email Alerting

Service

Receive free email alerts when new articles cite this article - sign up in the box at the top right corner of the article or click here.

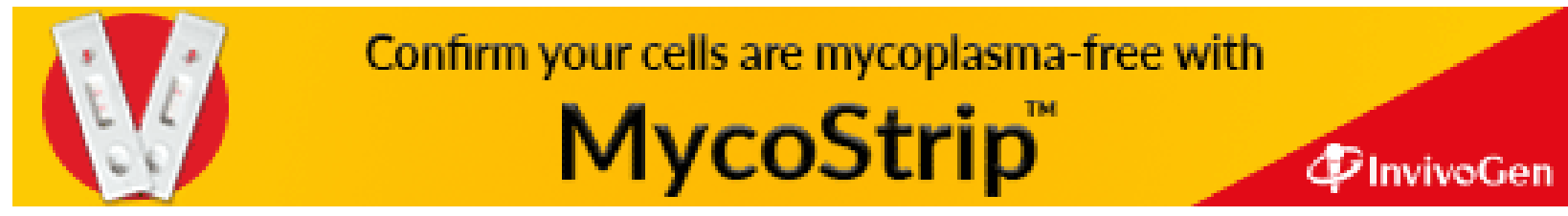

